Bangladesh J. Bot. 50(3): 969-976, 2021 (September) SpecialＤOI: https://doi.org/10.3329/bjb.v50i5.56452

\title{
SOIL NUTRIENT EVOLUTION UNDER DIFFERENT VEGETATION TYPES IN SEMI-ARID LOESS AREA
}

\author{
Lirong He ANd Yuhu Luo \\ Shaanxi Provincial Land Engineering Construction Group Co. Ltd., \\ Xi'an, Shaanxi, 710075, China \\ Keywords: Effects, Vegetation types, Soil nutrients, Loess area
}

\begin{abstract}
The soil nutrient characteristics under three vegetation types of arbor ( I ), shrub ( II ) and herb ( III ) were studied by mathematical statistics method combined with field investigation and indoor detection analysis. The change characteristics of soil nutrients under different land use patterns were discussed. The results showed that the average contents of soil organic matter, total nitrogen, available phosphorus and available potassium were 21.30 and $0.65 \mathrm{~g} / \mathrm{kg}, 3.67$ and $67.61 \mathrm{mg} / \mathrm{kg}$, respectively. Compared with grassland, woodland has better effect on fertilizer conservation in the Loess Plateau. In the process of soil nutrient improvement, the nutrient indexes such as organic matter, total nitrogen, available phosphorus and available potassium increased synchronously, and the soil alkaline environment that was not conducive to plant growth was also gradually improved. In the correlation between soil nutrients, available phosphorus and available potassium have good relative independence. In the future, organic fertilizer should be applied in this area, and nitrogen and phosphorus fertilizers should be supplemented to improve soil organic matter, nitrogen and phosphorus content, and to ensure soil nutrient balance by optimizing fertilization methods. In addition, in the case of uneven distribution of soil nutrients in the soil profile, it is recommended to take appropriate soil ploughing and reasonable human management measures to improve soil nutrient status, achieve high-quality sustainable development of soil, and promote the positive succession of vegetation communities.
\end{abstract}

\section{Introduction}

Soil is the basis of vegetation, which provides the necessary material basis for vegetation, and the appearance of vegetation also affects the formation and development process of soil (Binkley and Giardina 1998, Huang et al. 2010). Different types of vegetation community structure have different soil material circulation and energy transfer, and the characteristics of soil nutrients are of great significance to explore the soil fertility and nutrient element cycling mechanism of different types of vegetation communities (Del Río et al. 2017, Yin et al. 2017). Du et al. (2007) have shown that there are differences in the types and contents of soil nutrients in different plant community types. At the same time, soil nutrients in the same plant community type will be different due to different stages of succession (Wang et al. 1998).

Due to the lack and uneven distribution of precipitation, serious water loss, complex terrain and broken landform, the semi-arid loess region has different habitat conditions and different vegetation communities. The interaction between the characteristics of plant community structure and soil nutrients is affected by environmental conditions, and the interaction between the two is different in different regions. The ecological environment in loess region is fragile, and there are

*Author for correspondence: :<2015051029@nwafu.edu.cn> ${ }^{1}$ Shaanxi Provincial Land Engineering Construction Group Co., Ltd, Xi' an, Shaanxi, 710075, China. ${ }^{2}$ Institute of Land Engineering and Technology, Shaanxi Provincial Land Engineering Construction Group Co. Ltd., Xi'an, Shaanxi, 710075, China. ${ }^{3}$ Key Laboratory of Degraded and Unused Land Consolidation Engineering, the Ministry of Land and Resources, Xi'an, Shaanxi, 710075, China. ${ }^{4}$ Shaanxi Provincial Land Consolidation Engineering Technology Research Center, Xi' an, Shaanxi, 710075, China. 
some problems such as decreased productivity and land fertility. It is of great significance to study the relationship between the characteristics of plant community and the characteristics of soil nutrient distribution in loess region.

At present, many scientists have studied soil nutrients in loess area. The change characteristics of soil basic nutrients in perennial alfalfa grassland rotation farmland were studied. The results showed that spring wheat could maintain and balance the soil fertility in the growing season, while maize consumed more soil nutrients, resulting in seasonal decline of soil nutrients. Therefore, spring wheat should be rotated when grassland changed to farmland in semi-arid areas (Wang et al. 2005). Li et al. (2016) studied the vegetative organs of different tree species and the nutrient characteristics of soil, and found that the organic carbon content of Quercus Liaotungensis, Robinia pseudoacacia and Platycladus orientalis was higher, among which the growth of Robinia pseudoacacia and Platycladus orientalis were restricted by soil P and N, respectively. Previous studies on semi-arid loess regions mainly focused on soil nutrient characteristics under different agroforestry restoration measures, but relatively few studies focused on the interaction between vegetation community types at different natural succession stages and soil nutrient distribution characteristics.

In the present study, the arbor forest land, shrub land and grassland in Xiayukou of Hancheng city were taken as the research objects. Through the determination of soil acidity, conductivity and soil nutrient content under different vegetation types, the distribution characteristics of soil nutrients under different vegetation types were clarified. At the same time interaction between plant community structure and soil nutrients was elucidated. The purpose was to provide theoretical basis and data support for vegetation configuration and land use planning in semi-arid loess area.

\section{Materials and Methods}

The research area is located in Hancheng, Shaanxi Province, in the middle reaches of the Yellow River, namely, latitude $35^{\circ} 18$ '50 " $35^{\circ} 52^{\prime}$ ' 08" north, longitude $110^{\circ} 7$ '9 " 110 $37^{\prime}$ ' 24" east. The terrain is high in the northwest and low in the southeast, middle and low hills in the northwest and valley terraces in the southeast. It is $357 \sim 1783 \mathrm{~m}$ above sea level and close to the right bank of the Yellow River. From northwest to southeast, the land can be divided into four landform types: the middle and low mountain area, the loess plateau area, the loess plateau area and the valley terrace area. The annual average precipitation is $555.2 \mathrm{~mm}$, with uneven distribution within the year and great inter-annual variation with an annual average deviation of $106.9 \mathrm{~mm}$. Precipitation is mainly concentrated in summer and autumn. The average annual temperature is $13.7^{\circ} \mathrm{C}$, and the average daily temperature range of the whole year is $10.3^{\circ} \mathrm{C}$, with a large daily temperature range. The temperature distribution is higher in the Sichuan Plain and lower in the mountainous areas, and gradually increases from west to east. It belongs to the semiarid continental monsoon climate of warm temperate zone. The annual average sunshine is 2436 hrs, with the maximum in June and the minimum in November. The total solar radiation was $121.24 \mathrm{kcal} / \mathrm{cm}^{2} / \mathrm{a}$. The average frost-free period for many years is 208 days. The zonal vegetation type is deciduous broad-leaved forest with a wide variety of plants. Common trees include Pinus tabuliformis Carr., Pinus bungeana Zucc.), Platycladus orientalis (L.) Franco, Quercus wutaishansea Mary, etc., deciduous shrubs include Sophora viciifolia, Forsythia suspense, Osmanthus sp., Ostryopsis davidiana Decne., herbaceous plants include Themeda japonica (Willd.) Tanaka, Bothriochloa ischaemum (L.) Keng, Imperata cylindrica (L.) Beauv. and so on.

In June 2018, following the principles of typicality and representativeness, three plots with similar site conditions were selected in Xiayukou area of the test area. The vegetation community 
types were arbor forest land, shrub land and grassland, located at E110 $31^{\prime} 60^{\prime \prime}, \mathrm{N} 35^{\circ} 33^{\prime} 47^{\prime \prime}$, E110 $32^{\prime} 02^{\prime \prime}, \mathrm{N} 35^{\circ} 33^{\prime} 48^{\prime \prime}, \mathrm{E} 110^{\circ} 32^{\prime} 05^{\prime \prime}, \mathrm{N} 35^{\circ} 33^{\prime} 50^{\prime \prime}$, respectively. Each sample was selected three quadrats for sampling. Each sample was divided into surface layer $(0 \sim 50 \mathrm{~cm})$, middle layer $(50 \sim 100 \mathrm{~cm})$ and deep layer (below100 $\mathrm{cm}$ ) according to the section level. Each layer was randomly selected six locations and mixed into composite samples. After removing roots, litter and stone particles, the soil samples were thoroughly mixed. After drying in shade, $0.25 \mathrm{~mm}$ and 1 $\mathrm{mm}$ sieves were used for the determination of basic physical and chemical properties of soil.

Physical and chemical properties of soil were measured by conventional methods. Soil $\mathrm{pH}$ was determined by potentiometric method, electrical conductivity was determined by conductivity meter, organic carbon was determined by potassium dichromate oxidation-external heating method, total nitrogen was determined by Kjeldahl method, available phosphorus was determined by molybdenum antimony scandium colorimetric method, soil available potassium was determined by neutral ammonium acetate solution extraction-flame photometer method, available silicon was determined by citric acid extraction-colorimetric method, available boron was determined by methylimine- $\mathrm{H}$ colorimetric method, and exchangeable calcium was determined by EDTA volumetric method (Bo 2000 ).

Excel 2010 and Origin 9.0 were used for data processing and drawing. LSD method in SPSS $20.0(\mathrm{P}<0.05)$ was used for significance test and correlation analysis.

\section{Results and Discussion}

The soil nutrient indexes of the surface layer $(0-50 \mathrm{~cm})$, middle layer $(50-100 \mathrm{~cm})$ and deep layer (below $100 \mathrm{~cm}$ ) of each sample point were calculated as the average soil nutrient status of the sampling point. Then, the nutrient indexes of the same land use type were calculated as the arithmetic average (Table 1). The results showed that the average soil $\mathrm{pH}$ was 8.02 , the soil was slightly alkaline, and the spatial variability of $\mathrm{pH}$ value was small (5.7\%), which was consistent with the alkaline soil in the Loess Plateau. The REDOX potential was suitable for crop growth. The average content of soil organic matter was $21.30 \mathrm{~g} / \mathrm{kg}$, which had great spatial variability and the coefficient of variation was $51.6 \%$. The content of soil organic matter in the study area was low, which is consistent with previous studies. The average soil organic carbon density in the Loess Plateau area was only $23.65 \%$ of the national average soil organic carbon density (Peng et al. 2006). The average contents of total $\mathrm{N}$, available $\mathrm{P}$ and available $\mathrm{K}$ in soil were $0.65 \mathrm{~g} / \mathrm{kg}$, $3.67 \mathrm{mg} / \mathrm{kg}$ and $67.61 \mathrm{mg} / \mathrm{kg}$, respectively. According to the standards of the second national soil census (Table 2), the content of soil organic matter in the study area all belongs to the medium level 3, total $\mathrm{N}$ and available $\mathrm{P}$ belong to the very low level 5, and available $\mathrm{K}$ belongs to the low level 4 (National Soil Survey Office 1992). Spatial variation analysis of soil nutrients is the basis of soil nutrient management and rational fertilization, and its coefficient of variation is an internal reflection of soil properties, which can distinguish the sensitivity of different soil nutrients to resist external conditions (Xu and Liu 2004). In the research of soil science, it is generally considered that the variation coefficient of soil properties less than $10 \%$ is weak variation, the variation coefficient between 10 and $100 \%$ is medium variation, and the variation coefficient greater than $100 \%$ is strong variation. The variation coefficient of organic matter was the largest $(51.6 \%)$, followed by soil total $\mathrm{N}$ content (45.0\%), which was closely related to land use types. The contents of available $\mathrm{P}$ and available $\mathrm{K}$ in soil were mainly affected by the mineral composition of the parent material. Since loess was the most important parent material in the basin and its spatial distribution was relatively uniform, the variation coefficients of available $\mathrm{P}$ and available $\mathrm{K}$ were only 26.7 and $16.7 \%$, respectively. 
Table 1. The experiment design.

\begin{tabular}{llc}
\hline Treatment & Planting & $\begin{array}{c}\text { Thickness of } \\
\text { covering sand }\end{array}$ \\
\hline S1 & Perennial ryegrass & $7 \mathrm{~cm}$ \\
S2 & Perennial ryegrass & $11 \mathrm{~cm}$ \\
S3 & Perennial ryegrass & $15 \mathrm{~cm}$ \\
Ck & Perennial ryegrass & $0 \mathrm{~cm}$ \\
\hline
\end{tabular}

Table 2. Classification criteria of soil basic nutrients.

\begin{tabular}{lcccc}
\hline Level & $\mathrm{SOM}(\%)$ & $\mathrm{TN}(\%)$ & $\mathrm{AP}(\mathrm{mg} / \mathrm{kg})$ & $\mathrm{AK}(\mathrm{mg} / \mathrm{kg})$ \\
\hline Very rich & $>4$ & $>0.2$ & $>40$ & $>200$ \\
Rich & $3 \sim 4$ & $0.15 \sim 0.2$ & $20 \sim 40$ & $150 \sim 200$ \\
Medium & $2 \sim 3$ & $0.1 \sim 0.15$ & $10 \sim 20$ & $100 \sim 150$ \\
Poor & $1 \sim 2$ & $0.07 \sim 0.1$ & $5 \sim 10$ & $50 \sim 100$ \\
Scarce & $0.6 \sim 1$ & $0.05 \sim 0.07$ & $3 \sim 5$ & $30 \sim 50$ \\
Extremely scarce & $<0.6$ & $<0.05$ & $<3$ & $<30$ \\
\hline
\end{tabular}

Soil organic matter and total $\mathrm{N}$ were significantly different in different land use types. The order of soil organic matter and total $\mathrm{N}$ contents from high to low was as follows: tree land > shrub land > grassland, and there was no significant difference between shrub land and grassland. The content of soil organic matter and total $\mathrm{N}$ in forest land was significantly higher than that of other land use types, which indicate that the forest land with higher vegetation cover has less disturbance from human activities, plant residues and dead leaves have accumulated in the soil surface for many years, and the decay effect is obvious, and the content of soil organic matter is higher (Jiang et al. 2005). Among the three land use types, the contents of organic matter, total nitrogen and available phosphorus in grassland soil were the lowest. According to the second national soil census standard, the contents of organic matter, total nitrogen and available phosphorus in grassland soil belonged to the scarcity level, and the soil nutrients were significantly lower, which was closely related to the spatial distribution characteristics of grassland in Xiayukou area of Hancheng city. Grasslands are mostly distributed on steep slopes or on both sides of gullies and rivers, with sparse vegetation coverage, serious soil and water loss and poor nutrient conditions.

The analysis of variance showed that land use had no significant effect on soil available K. According to the second national soil survey standard, the contents of available $\mathrm{K}$ in arbor forest, shrub land and grassland were all in the state of lack of grade. Soil K content of different land uses had no obvious difference (Table 3). Although the application of potassium fertilizer can increase the content of soil available $\mathrm{K}$, it has little effect on soil total $\mathrm{K}$, which is mainly affected by the mineral composition of parent material ( $\mathrm{Gu}$ et al. 2004). The content of available $\mathrm{K}$ is obviously low, which indicates that the local use of potassium fertilizer is insufficient. 
Table 3. Soil nutrient characteristics of different land use types.

\begin{tabular}{lcccccc}
\hline Types & $\begin{array}{c}\text { SOM } \\
(\mathrm{g} / \mathrm{kg})\end{array}$ & $\begin{array}{c}\text { TN } \\
(\mathrm{g} / \mathrm{kg})\end{array}$ & $\begin{array}{c}\mathrm{AP} \\
(\mathrm{mg} / \mathrm{kg})\end{array}$ & $\begin{array}{c}\mathrm{AK} \\
(\mathrm{mg} / \mathrm{kg})\end{array}$ & $\mathrm{pH}$ & $\begin{array}{c}\text { Eh } \\
(\mathrm{mV})\end{array}$ \\
\hline I & $31.85 \pm 7.07^{\mathrm{a}}$ & $0.93 \pm 0.25^{\mathrm{a}}$ & $4.47 \pm 0.53^{\mathrm{a}}$ & $78.83 \pm 12.06^{\mathrm{a}}$ & $7.63 \pm 0.15^{\mathrm{a}}$ & $525.00 \pm 6.96^{\mathrm{a}}$ \\
II & $18.10 \pm 10.00^{\mathrm{b}}$ & $0.49 \pm 0.23^{\mathrm{b}}$ & $3.93 \pm 0.76^{\mathrm{a}}$ & $60.00 \pm 7.10^{\mathrm{b}}$ & $8.10 \pm 0.60^{\mathrm{a}}$ & $516.67 \pm 3.98^{\mathrm{a}}$ \\
III & $13.88 \pm 6.88^{\mathrm{b}}$ & $0.53 \pm 0.19^{\mathrm{b}}$ & $2.56 \pm 0.40^{\mathrm{b}}$ & $64.00 \pm 1.55^{\mathrm{b}}$ & $8.32 \pm 0.19^{\mathrm{a}}$ & $518.83 \pm 23.95^{\mathrm{a}}$ \\
\hline
\end{tabular}

Due to the influence of physical and chemical processes such as litterfall and crust, the soil surface layer showed obvious nutrient enrichment (Wang et al. 2010). From the surface, middle and deep soil nutrient comparison (Figs 1-4), surface soil organic matter, total nitrogen, available phosphorus and available potassium were significantly higher than those of middle and deep soil. Nutrient indicators showed a sharp downward trend, soil nutrients showed surface enrichment. Xu and Liu (2004) reported that surface soil nutrients are more sensitive to external conditions, vegetation and soil environmental factors mainly affect the surface soil nutrients. In general, soil available phosphorus, available potassium, organic matter and total nitrogen have obvious surface aggregation characteristics, and these four nutrients are closely related to crop growth. At present, the distribution of soil nutrient profiles under three types of land in the region is conducive to crop growth. The distribution of soil organic matter and total nitrogen in the $80 \mathrm{~cm}$ section of arbor forest land was uniform, while the content of soil organic matter and total nitrogen in the section of shrub land and grassland was different, so it was necessary to improve the distribution characteristics of soil organic matter and total nitrogen.

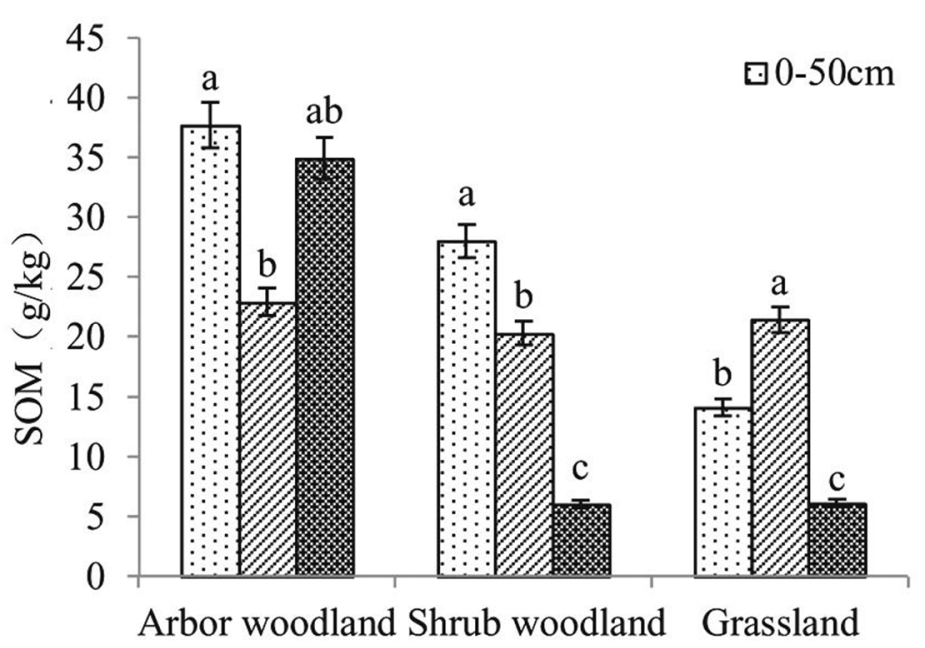

Fig. 1. Soil organic matter content in different land use types.

In order to reveal the change rule of soil nutrient indexes during the change process, the correlation analysis of soil basic nutrient indexes was carried out (Table 4). The results showed that there was a significant positive correlation between organic matter, total nitrogen, available phosphorus and available potassium, and the correlation coefficient was between 0.54 and 0.94 , and the correlation was more than 0.01 confidence test. This indicated that there was a 
synchronous increase in organic matter, total nitrogen, available phosphorus and available potassium during the improvement of soil nutrients. Organic matter was significantly correlated with total nitrogen, available phosphorus and available potassium, which was consistent with other research results. Organic matter was the key indicator to characterize soil quality in hilly areas of the Loess Plateau (Xu and Liu 2004). With the increase of soil nutrients, soil $\mathrm{pH}$ showed a downward trend, which was related to the gradual improvement of soil alkaline environment that was not conducive to plant growth in the process of soil improvement by vegetation and human transformation. It was also found that there was no significant correlation between available phosphorus, total nitrogen, and available potassium, as well as with other indicators, and it had good independence.

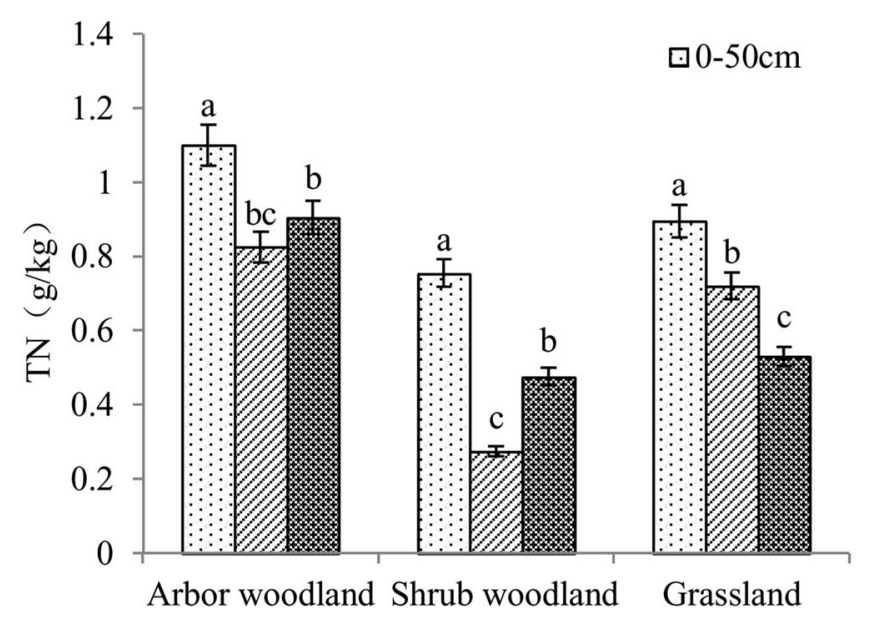

Fig. 2. Soil total nitrogen content in different land use types.

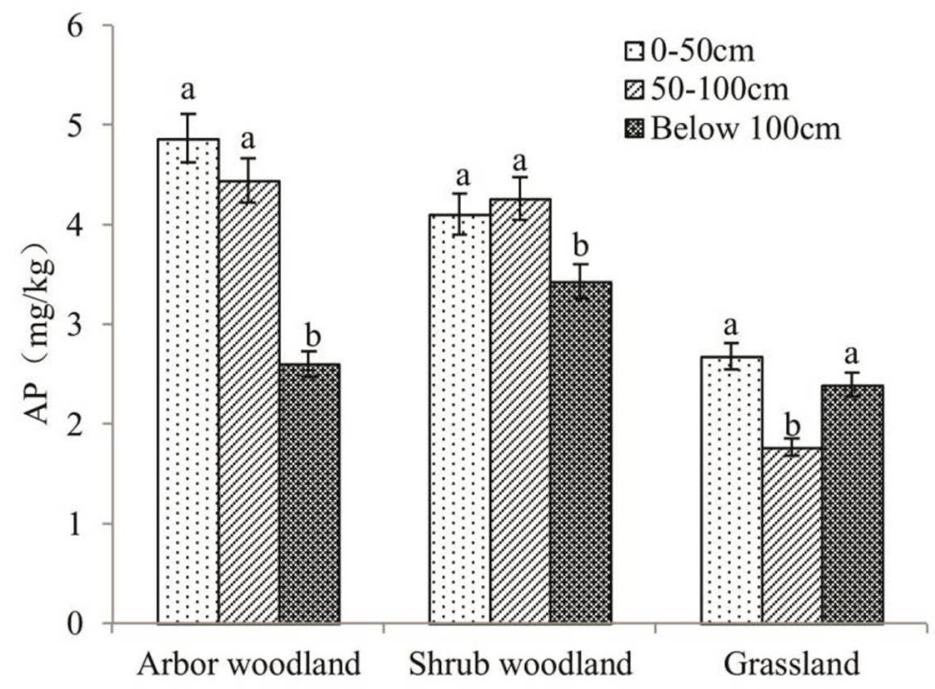

Fig. 3. Soil available P content in different land use types. 


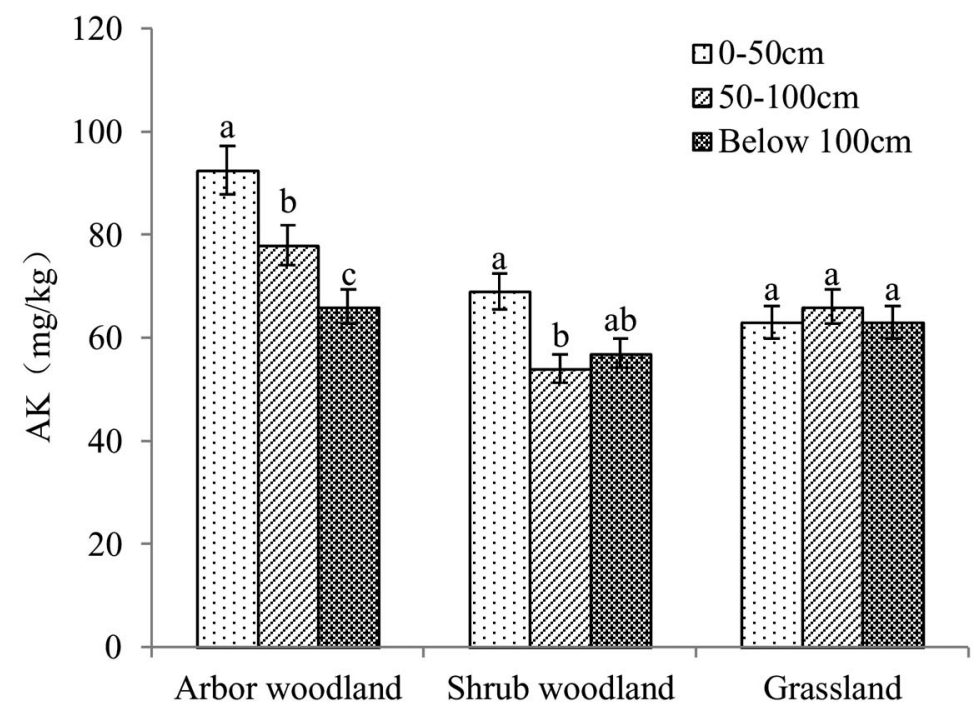

Fig. 4. Soil available potassium content in different land use types.

Table 4. Correlation among soil nutrient indexes

\begin{tabular}{ccccccc}
\hline & $\mathrm{pH}$ & Eh & SOM & TN & AP & AK \\
\hline $\mathrm{pH}$ & 1 & & & & & \\
$\mathrm{Eh}$ & -0.2707 & 1 & & & & \\
$\mathrm{SOM}$ & -0.7526 & 0.4849 & 1 & & & \\
$\mathrm{TN}$ & -0.4150 & 0.2142 & 0.4521 & 1 & & \\
$\mathrm{AP}$ & 0.1985 & -0.2132 & -0.3534 & -0.2442 & 1 & \\
$\mathrm{AK}$ & 0.0403 & 0.0919 & -0.0539 & 0.2620 & 0.4095 & 1 \\
\hline
\end{tabular}

From the present findings it may be inferred that soil nutrients are basically in deficit or extremely deficit level. In future, organic fertilizer should be applied in this region, and nitrogen and phosphorus fertilizers should be supplemented to improve the contents of soil organic matter, nitrogen and phosphorus. By optimizing fertilization methods, soil nutrient balance can be ensured and soil sustainable development can be promoted.

Secondly effects of different land use patterns on the contents of soil organic matter, total $\mathrm{N}$ and available $\mathrm{P}$ were found to be significant. Soil fertility, organic matter, total $\mathrm{N}$ and available $\mathrm{P}$ contents of forest land was determined to be significantly higher than the grassland and that's why grassland soil nutrients were revealed to be the worst. Compared with grassland, woodland has better effect on fertilizer conservation in the Loess Plateau. In view of the uneven distribution of nutrient profile, it is recommended to improve the soil nutrient status by covering soil and reasonable human management measures.

Finally in the process of soil nutrient improvement, there was a law of simultaneous increase in organic matter, total nitrogen, available phosphorus and available potassium, which was not conducive to the gradual improvement of soil alkaline environment for plant growth. In the 
correlation between soil nutrients, available phosphorus and available potassium have good independence.

\section{Acknowledgements}

The project was supported by Natural Science Basic Research Plan in Shaanxi Province of China (2021JQ-960) and the projects of Land Engineering Construction Group of Shaanxi Provincial (DJNY2020-19 and DJNY2021-27).

\section{References}

Binkley D and Giardina C 1998. Why do tree species affect soils? the warp and woof of tree-soil interactions. Biogeochemistry (Dordrecht), 42(1-2): 89-106.

Bo SD 2000. Soil Chemical Analysis, Nanjing Agricultural University.Beijing:China Agriculture Press.

Del Río M, Pretzsch, Hans, Ruíz-Peinado and Ricardo 2017. Species interactions increase the temporal stability of community productivity in Pinus sylvestris-Fagus sylvatica mixtures across Europe. J Ecol, 105(4): 1032-1043.

Du F, Liang ZS and Xu XX 2007. Effects of community biomass and vegetation soil nutrients on abandoned grassland in the loess hilly region of northern Shaanxi Province. Acta Ecol. Sin. 27(5): 1673-1683.

Gu QZ, Yang XY and Sun BH 2004. Effects oflong-term fertilization on soil nutrition and land productivity in top-soil of Loess Soil. Acta Agriculturae Boreali-occidentalis Sinica, 13(3): 121-125.

Huang Chang-yong, Xu Jian-ming 2010. Soil. Third edition. Beijing:China Agriculture Press.

Jiang YJ, Yuan DX and Zhang C 2005 Impact of land use change on soil properties in a typical Karstagricultural region: A case study of Xiaojiang watershed, Yunnan. Acta Geograph Sin. 60(5): 751760.

Li H, Wang BT and Liu T 2016. Changes of soil nutrient contents of different forest tree species and forest land in loess area of western Shannxi. Forest Res. 29(04): 587-595.

National Soil Survey Office 1992. Technology of China Soil Survey. Beijing: China Agricultural Press, 31111.

Peng WY, Zhang KL and Yang QK 2006. Forecast of impact of the retur-ning farms to forests on soil organic carbon of Loess Plateau. Areal Res. Develop. 25(3): 94-99.

Wang J, Li FM, Jia Y and Wang YJ 2005. Soil nitrogen, phosphorus and organic matter in alfalfa rotation cropland in semi-arid loess region. Chinese J. Appl. Ecol. 2005(03): 439-444.

Wang R, Zhu QK and Bu N 2010. Study on physicochenmical properties of bi-ological soil crusts in the Hilly-Gully regions of the Loess Plateau. Arid Zone Res. 27( 3): 401-408.

Wang Y, Wang Y and Wang Y 1998 Soil nutrient status and soil nutrient status in Chinese fir, Pinus massoniana and Castanopsis eyrei stands. Forest Res. 11(6): 586-591.

Xu MX and Liu GB 2004. The characteristics and evolution of soil nutrientin artificial black locust (Robinia pseudoacacia) forest land in theHilly Loess Plateau. Plant Nutri. Fertilizing, 10(1): 40-46.

Yin C, Shi QM and Zhao X 2017 The role of tamarisk in the spatial heterogeneity of soil resources in the northern Tarim Basin, Xinjiang, China. Plant Soil, 420(IA): 523-538. 